\title{
PRORAČUN ČELIČNE HALE PREMA EVROKODU I UPOREDNA ANALIZA KRANSKE STAZE PREMA EVROKODU I SRPS-U
}

\section{STRUCTURAL DESIGN OF STEEL HALL ACCORDING TO EUROCODE AND COMPARATIVE ANALYSIS OF RUNWAY BEAM TO EUROCODE AND SRPS}

\author{
Branko Ilić, Fakultet tehničkih nauka, Novi Sad
}

\begin{abstract}
Oblast - GRAĐEVINARSTVO
Kratak sadržaj - Tema rada je proračun čelične proizvodne hale prema Evrokod propisima sa uporednom analizom kranske staze prema Evrokodu $i$ SRPS-u. Urađen je kompletan statički proračun i dimenzionisanje sa potrebnim grafičkim prilozima (detaljima čelika, detaljima veza, detaljima armiranja).
\end{abstract}

Ključne reči: Čelična hala, kranska staza, Evrokod, detalji čelika, detalji veza

\begin{abstract}
The topic of the paper is the structural design of the steel hall according to Eurocode standards with a comparative analysis of the crane supporting beam according to Eurocode and SRPS. A complete static calculation and structural design was done with the necessary graphic attachments (steel details, connections details, reinforcement details).
\end{abstract}

Ključne reči: Steel hall, crane supporting beam, Eurocode, steel details, conections details

\section{UVOD}

Projektnim zadatkom definisani su ulazni podaci potrebni za projektovanje proizvodne čelične hale dimezija $u$ osnovi $27 \times 56 \mathrm{~m}$. Da bi se obezbedila funkcionalnost objekta predviđen je mostni kran nosivosti 200 t. Zadata lokacija hale je Valjevo. Lokacija objekta utiče na uticaje koje treba analizirati pri proračunu a to su vetar, sneg, seizmičko opterećenje i druga.

\section{ANALIZA OPTEREĆENJA}

Analizom opterećenja obuhvaćena su sva opterećenja koja će se javiti za vreme ekspoatacionog veka konstrukcije. Evrokod EN 1990 definiše načine na koje treba proračunavati dejstva i kako ih naneti na konstrukciju.

\subsection{Stalno opterećenje}

Ovo opterećenje obuhvata sopstvene težine konstruktivnih i nekonstruktivnih elemenata. U nekonstruktivne elemente se ubrajaju obloge odnosno zidni i krovni paneli zatim elektro i mašinske instalacije kao i sva druga oprema koja se koristi u procesu proizvodnje a stalnog je karaktera. Sopstvena težina konstruktivnih elemenata uračunata je automatizmom samog softvera koji je korišćen za proračun a to je Tower 7 .

\section{NAPOMENA:}

Ovaj rad proistekao je iz master rada čiji mentor je bio prof. dr Đorđe Lađinović.

\subsection{Povremeno opterećenje}

Opterećenje od snega definisano je Evrokodom EN 19911-3. Osnovni parametar za definisanje intenziteta ovog dejstva je opterećenje od snega na tlo $s_{k}=1,40 \mathrm{kN} / \mathrm{m}^{2}$. Ovaj intenzitet se očitava sa karti u zavisnosti od lokacije objekta. Pored ove vrednosti na intenzitet opterećenja od snega utiču još i koeficijent oblika $\mu_{i}$ koji je funkcija oblika krova, koeficijent izloženosti $C_{e}$ i toplotni koeficijent $C_{t}$. Konačno intenzitet opterećenja od snega dobija se prema izrazu (1):

$$
s=\mu_{i} * C_{e} * C_{t} * s_{k}
$$

Opterećenje od vetra definisano je Evrokodom EN 19911-4. Deluje pritiskujuće ili sišuće na zidne i krovne površine. Osnovni prametar za definisanje dejstva vetra je osnovna fundamentalna brzina vetra koja se takođe u zavisnosti od lokacije obejkta očitava sa karti i za ovaj objekat iznosi $V_{b, 0}=21 \mathrm{~m} / \mathrm{s}$. Na osnovu ove brzine računa se udarni pritisak vetra koji se množi sa koeficijentima pritiska na spoljašnje ili unutrašnje površine i na taj način dobija konačno opterećenje koje se nanosi na objekat. Korigovanjem ove brzine sa direkcionim $C_{\text {dir }}$ i sezonskim koeficijentom $C_{\text {season }}$ dobija se osnovna brzina vetra prema izrazu (2), a korigovanjem osnovne brzine vetra koeficijentom hrapavosti $C_{r(z)}$ i koeficijentom topografije $C_{o(z)}$ dobija se srednja brzina vetra prema izrazu (3):

$$
\begin{aligned}
& V_{b}=V_{b, 0} * C_{d i r} * C_{\text {season }} \\
& V_{m(z)}=V_{b} * C_{r(z)} * C_{o(z)}
\end{aligned}
$$

$\mathrm{U}$ formuli za računanje udarnog pritiska vetra prema izrazu (4) figurišu koeficijent turbulencije $I_{v(z)}$, gustina vazduha $\rho$ i srednja brzina vetra $V_{m(z)}$.

$$
q_{p(z)}=\left(1+7 * I_{v(z)}\right) * \frac{1}{2} * \rho * V_{m(z)}^{2}
$$

$\mathrm{Na}$ kraju, intenzitet pritiska vetra na spoljašnje površine dobija se prema izrazu (5) na osnovu koeficijenta pritiska koji zavisi od karakteristika površine na koju vetar deluje.

$$
w_{e}=q_{p(z)} * C_{p e}
$$

\subsection{Seizmičko opterećenje}

Seizmičko opterećenje definisano je Evrokodom EN 1998 i podrazumeva najpre proračun modalne analize konstrukcije koja nam daje uvid $u$ dinamičke karakteristike same konstrukcije. Ti podaci, tačnije periodi oscilovanja, osnova su za dalji proračun 
seizmičkog opterećenja. U tabeli 1 dati su, za prvih deset tonova, periodi oscilovanja sa odgovarajućim frekvencijama oscilovanja konstrukcije.

Tabela 1. Rezultati modalne anlalize

\begin{tabular}{|c|r|r|}
\hline No & $\mathrm{T}[\mathrm{s}]$ & $\mathrm{f}[\mathrm{Hz}]$ \\
\hline 1 & 1.0507 & 0.9517 \\
\hline 2 & 0.8820 & 1.1338 \\
\hline 3 & 0.6658 & 1.5019 \\
\hline 4 & 0.4236 & 2.3608 \\
\hline 5 & 0.2822 & 3.5430 \\
\hline 6 & 0.2213 & 4.5191 \\
\hline 7 & 0.2040 & 4.9015 \\
\hline 8 & 0.1728 & 5.7877 \\
\hline 9 & 0.1513 & 6.6109 \\
\hline 10 & 0.1470 & 6.8019 \\
\hline
\end{tabular}

Lokacija objekta definisala je maksimalno referentno ubrzanje tla $a_{g R}=0,15 g$ koje je još jedan od osnovnih parametara za dalji proračun. Bitni parametri su još karakteristike tla, za ovaj objekat izabrano tlo kategorije B, klasa duktilnosti DCM i klasa značaja objekta, ovde izabrana II. Izabrana je multimodalna spektralna analiza za proračun seizmičkih sila. Zemljotresno kretanje neke tačke na površini tla opisuje se elastičnim spektrom odgovora prikazanim na slici 1 .

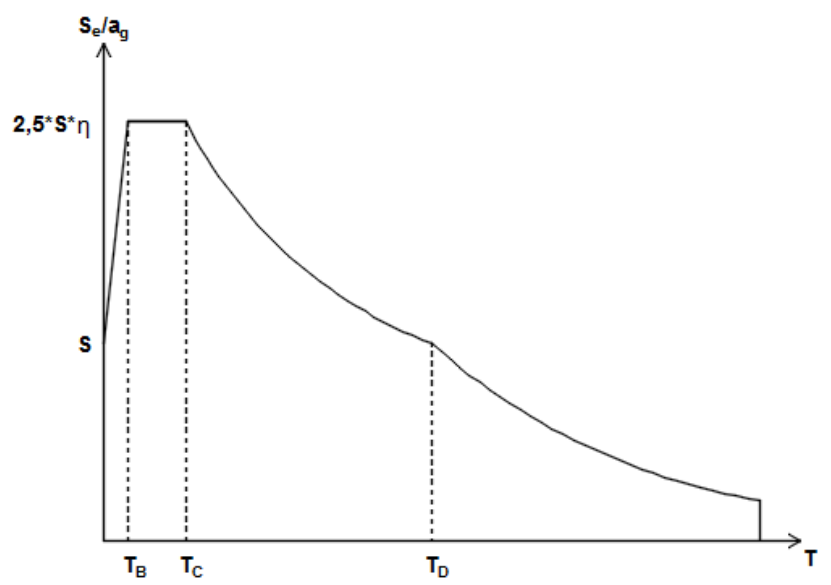

Slika 1. Elastični spektar odgovora

Redukovanjem elastičnog spektra odgovora faktorom ponašanja dobija se projektni spektar odgovora $S_{d}\left(T_{k}\right)$. Ukupna horizontalna seizmička sila za k-ti ton dobija se prema izrazu (6) gde je $m_{k}$ efektivna modalna masa za kti ton oscilvanja.

$$
F_{b k}=S_{d}\left(T_{k}\right) * m_{k}
$$

Svakom tonu oscilovanja odgovara određena bazna sila a samim tim i uticaji od seizmičkog dejsta za taj ton. Maksimalna vrednost nekog uticaja od seizmičkog dejstva određena je primenom CQC metode (kompletna kvadratna kombinacija) prema izrazu (7).

$$
E_{E}=\sqrt{\sum_{n} \sum_{m} E_{E, n} * \rho_{n m} * E_{E, m}}
$$

Za ovaj objekat računate su seizmičke sile za globalni $x$ i $y$ pravac. Ove dve komponente seizmičkog dejstva smatra se da deluju istovremeno. Maksimalna vrednost nekog uticaja u konstrukciji može se konzervativno uzeti kao srednja kvadratna vrednost (SRSS) prema izrazu (8).

$$
E_{E}=\sqrt{E_{E x}^{2}+E_{E y}^{2}}
$$

\subsection{Opterećenje od kranske staze}

Mosna dizalica je raspona $25,5 \mathrm{~m}$ sistema proste grede oslonjena na kranske staze koje se protežu celom dužinom hale. Nosivost krana je 200 t. Tabelom 2 date su karakteristike krana koji opslužuje halu.

Tabela 2. Karakteristike krana

\begin{tabular}{|l|c|}
\hline \multicolumn{2}{|c|}{ Dvogredna mosna dizalica sa jednom kukom } \\
\hline Nosivost & $20 \mathrm{t}=200 \mathrm{kN}$ \\
\hline Raspon & $25,5 \mathrm{~m}$ \\
\hline Sopstvena težina krana & $20 \mathrm{t}=200 \mathrm{kN}$ \\
\hline Težina mačke & $10 \mathrm{kN}$ \\
\hline Brzina dizanja tereta & $4 \mathrm{~m} / \mathrm{min}$ \\
\hline Razmak točkova & $4,0 \mathrm{~m}$ \\
\hline Klasa dizanja & $\mathrm{HC} 4$ \\
\hline Klasa zamora & $\mathrm{S} 6$ \\
\hline
\end{tabular}

Opterećenje od krana definisano je Evrokodom 1991-3. Podrazumeva analizu opterećenja koja deluju $u$ vertikalnom, podužnom i poprečnom pravcu. Klasifikuju se kao promenljiva i incidentna dejstva. Na slici 2 prikazan je raspored vertikalnog opterećenja od krana za dobijanje maksimalnih uticaja na kranskoj stazi. Na slici 3 prikazane su podužne horizontalne sile usled ubrzanja i kočenja krana a na slici 4 poprečne horizontalne sile usled istog dejstva. Horizontalne sile uzrokovane iskošenjem krana date su na slici 5.

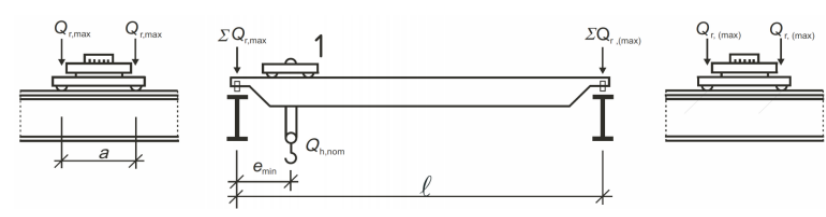

Slika 2. Raspored opterećenja za maksimalne uticaje

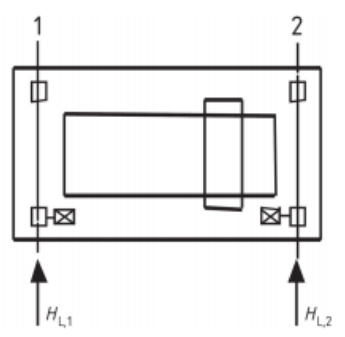

Slika 3. Podužne horizontalne sile

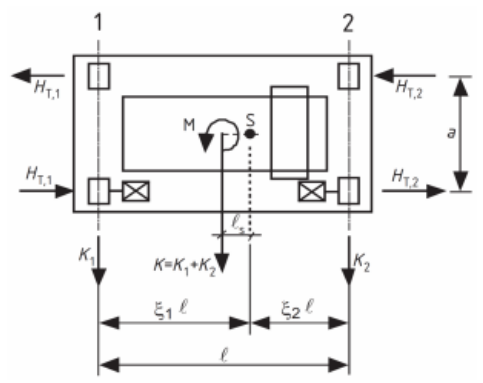

Slika 4. Poprečne horizontalne sile 


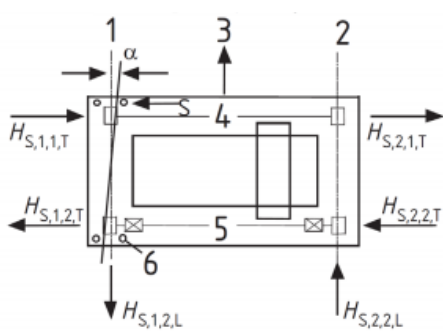

Slika 5. Horizontalne sile usled iskošenja krana

Kako je opterećenje od krana izrazito dinamičkog karaktera u proračun se uvode dinamički koeficijenti kojima se uvećavaju dejstva u zavisnosti od vrste samog opterećenja. Ukupno ima sedam različitih dinamičkih koeficijenata koji se koriste pri proračunu. Evrokod propisuje sedam grupa opterećenja od kojih se sve moraju proveriti a one merodave koristiti za proračun. U ovom radu nisu analizirana incidenta dejstva od krana.

\section{MODELIRANJE KONSTRUKCIJE I OPTEREĆENJA}

Modeliranje konstrukcije rađeno je u programu Tower 7. Za proračun konstrukcije primenjena je metoda konačnih elemenata. Svi čelični konstruktivni elementi, a to su stubovi, grede, spregovi, rožnjače i kranska staza modelirani su linijskim konačnim elementima. Istim konačnim elementima modelirane su temeljne grede i temeljni stubovi. Temeljne stope su modelirane površinskim konačnim elementima. Na slici 6 prikazan je 3D model konstrukcije.

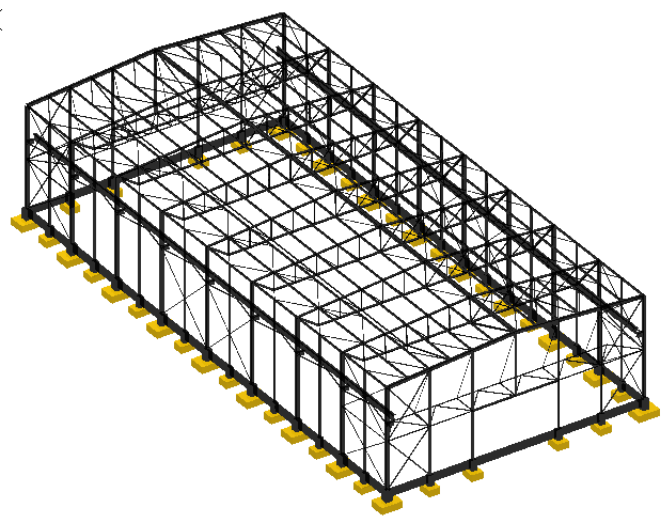

Slika 6. 3D model konstrukcije

Beton je klase C30/37 a čelik je kvaliteta S275. Modeliranje oslonaca odnosno interakcije tla $i$ konstrukcije vršeno je primenom Winkler-ovog modela. Osnovni parametar za korišćenje ovog načina modeliranja oslonaca je koeficijent posteljice $k$ koji se izražava $\mathrm{u}$ $k N / m^{2} / m$. U globalnom $z$ pravcu iznosi $k=$ $10000 \mathrm{kPa} / \mathrm{m}$. U horizontalnom pravcu je $k=$ $5000 \mathrm{kPa} / \mathrm{m}$. Opterećenja su u zavisnosti od karaktera i samih propisa modelirana kao površinska odnosno linijska. Sopstvena težina nekonstruktivnih elemenata, sneg i vetar naneti su kao površinska opterećenja koja deluju po linijskom rasporedu na konstruktivne elemente. Opterećenje od krana na kransku stazu modelirano je kao pokretno linijsko opterećenje dve koncentrisane sile. Seizmičko opterećenje je naneto na konstrukciju automatizmom programa.

\section{STATIČKI PRORAČUN I DIMEZIONISANJE}

Statički proračun je rađen linearnom teorijom prvog reda. Dimenzionisanjem elementa konstrukcije proverava se zadovoljenje graničnog stanja nosivosti i graničnog stanja upotrebljivosti koristeći Evrokod EN 1992 i EN 1993, za betonske i čelične elemente, respektivno.

\subsection{Proračunske kontrole}

Kontrola napona u tlu podrazumeva zadovoljenje zahteva propisanih standardom EN 1997 kao i maksimalnih projektnih napona koji se ne smeju prekoračiti a koji su deo geomehaničkog elaborata. Iz proračuna sledi da je maksimalni proračunski napon manji od projektne nosivosti tla što je dato izrazom (9).

$$
E_{E d}=194,99 \mathrm{kPa}<R_{d}=200,00 \mathrm{kPa}
$$

Kontrola normalnih napona u stubovima je zahtev Evrokoda 8. Aksijalnu silu pritiska potrebno je ograničiti na $30 \%$ proračunske nosivosti stuba. Ovo ograničenje za uzrok ima potrebu za obezbeđenjem dovoljnog duktilnog rada kritičnih peseka pri seizmičkim uticajima imajući u vidu da sa porastom sile pritiska opada duktilnost preseka. Uslov koji mora biti zadovoljen dat je izrazom (10). Proračunska vednost plastične nosivosti bruto poprečnog preseka označena je sa $N_{p l, R d}$.

$$
N_{E d}=0,3 * N_{p l, R d}
$$

Kontrola obuhvatanja efekata drugog reda je još jedan od zahteva Evrokoda 8. Potrebno je uporediti odnos između momenata drugog reda koje pravi aksijalna sila u stubu i momenata prvog reda koje pravi horizontalna sezmička sila. Ukoliko ovi odnosi nisu u granici dozvoljenih potrebno je efekte drugog reda obuhvatiti na neki od načina koje propisuje Evrokod. Parametar koji određuje uvođenje efekata drugog reda je koeficijent osetljivosti $\theta$. Izrazom 11 dat je način proračuna ovog koeficijenta. Vrednosti koeficijenta većeg od 0,3 nisu dozvoljene. Od 0,2 do 0,3 zahteva se nelinearna analiza konstrukcije. Vrednost koeficijenta od 0,1 do 0,2 podrazumeva uvećanje proračunskih momenata ali bez nelinearne analize, dok za vrednosti manje od 0,1 nije potrebno uvoditi efekte drugog reda u proračun na bilo koji način.

$$
\theta=\frac{P_{\text {tot }} * d_{r}}{V_{\text {tot }} * h}=\frac{M_{\text {II reda }}}{M_{\text {Ireda }}}
$$

Kao i prethodni zahtevi kontrola dopuštenih pomeranja vrha stuba je zahtev Evrokoda 8. U ovom slučaju proveravaju se realna pomeranja koja nastaju pri seizmičkom dejstvu na konstrukciju. Pomeranje vrha stuba $d_{r, k}$ mora se zadovoljiti prema izrazu (12). Redukcionim faktorom $v$, koji zavisi od klase značaja objekta, umanjuje se ova vrednost. Dozvoljeno pomeranje zavisi od visine stuba $h_{k}$, koja je redukovana faktorom $\omega$, koji zavisi od vrste nekonstruktivnih elemenata.

$$
d_{r, k} * v \leq \omega * h_{k}
$$

\subsection{Kombinovanje opterećenja}

Prilikom projektovanja razmatraju se najnepovoljnije kombinacije opterećenja koje mogu istovremeno opterećivati konstrukciju. U tim kombinacijama razlikovaćemo dejstva koja u posmatranim presecima 
imaju povoljan efekat (deluju povoljno), odnosno ne formiraju merodavnu kombinaciju opterećenja (izostaju iz kombinacije) ili se obračunavaju sa svojim minimumom (stalna dejstva). Prilikom kombinovanja, dejstva se, za proračun prema graničnom stanju loma, uvećavaju parcijalnim koeficijentima sigurnosti, što omogućava rezervu nosivosti elemenata i konstrukcije. To znači da su proračunska dejstva veća od stvarnih inteziteta dejstava, što upravo daje pomenutu rezervu nosivosti odnosno stepen sigurnosti. Za svaki kritičan slučaj opterećenja, proračunske vrednosti uticaja od dejstava, moraju da budu određene kombinovanjem vrednosti dejstava za koja se smatra da mogu da se pojave istovremeno. Pravilo za kombinovanje za stalne i prolazne proračunske situacije prikazano je izrazom (13), a pravilo kombinovanja za seizmičke proračunske situacije izrazom (14).

$$
\begin{gathered}
\sum_{j \geq 1} \gamma_{G, j} G_{k, j}+\gamma_{p} P+\gamma_{Q, 1} Q_{k, 1}+\sum_{i>1} \gamma_{Q, i} \psi_{0 . i} Q_{k, i} \\
\sum_{j \geq 1} G_{k, j}+P+A_{E d}+\sum_{i>1} \psi_{2 . i} Q_{k, i}
\end{gathered}
$$

\subsection{Proračun konstruktivnih elemenata}

Ovom proračunu prethodi kombinovanje opterećenja. Ove kombinacije su korišćene za proveru graničnog stanja nosivosti. Za granično stanje upotrebljivosti korišćene su karakteristične kombinacije opterećenja.

Pri proračunu elemenata konstrukcije, u zavisnosti od uticaja koji se javljaju na njima, proveravano je sledeće: kontrola napona, računska otpornost na pritisak, računska otpornost na zatezanje, računska otpornost na savijanje, proračunska nosivost na smicanje, proračunska nosivost na savijanje i aksijalnu silu, proračunska nosivost na savijanje i smicanje, proračunska nosivost na savijanje, smicanje i aksijalnu silu, nosivost na fleksiono izvijanje, nosivost na bočno-torziono izvijanje. Proveravani su i vertikalni i horizontalni ugibi u zavisnosti od položaja konstruktivnog elementa $\mathrm{u}$ konstrukciji. U okviru proračuna detaljno je obrađena kranska staza prema Evrokodu i prema domaćim SRPS propisima što je istraživački deo rada.

Pored gore pomenutih kontrola za kransku stazu proveravana je i nosivost na dejstvo smicanja i torzije. Torzija na kranskoj stazi nastaje usled slučajnog ekscentriciteta koji pravi točak krana na šini po kojoj se kreće i usled horizontalnih bočnih sila. Na slici 7 je prikazana.

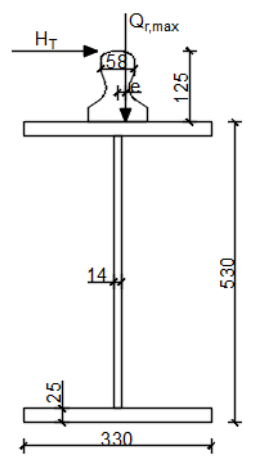

Slika 7. Sile koje prave torziju na kranskoj stazi
Proveravano je i ulubljenje (crippling) što pretstavlja izbočavanje i plastifikaciju rebra neposredno ispod nožice usled koncentrisane sile.

Analiza opterećenja prema SRPS obuhvatila je vertikalne sile od točkova krana, podužne sile od ubrzanja i kočenja i poprečne sile od bočnih udara. Intezitet vertikalnih sila izračunat je na osnovu sopstvene težine krana i nosivosti krana za najnepovoljniji položaj opterećenja. Sile kočenja prema SRPS-u iznose 1/7 vertikalnog opterećenja točka. Intenzitet poprečnih sila od bočnih udara uzima se kao $1 / 10$ vertikalnog opterećenja točka.

\section{ZAKLJUČAK}

U delu zaključka pomenute su osnovne činjenice proistekle iz uporedne analize proračuna kranske staze prema Evrokodu i SRPS standardu, što je i istraživački deo ovog projekta. Uvođenje Evrokod propisa ima za osnovni cilj racionalizaciju poprečnih preseka dostižući granična stanja nosivosti, nasuprot ranijem pristupu koji se temelji na metodi dopuštenih napona gde su elementi korišćeni u linearnom radu dostižući maksimalno granicu razvlačenja. Očikavano bi zbog svega bilo da je za jedan isti poprečni presek veća proračunska iskorišćenost koristeći SRPS standard. Međutim kako se u Evrokodu za opterećenja koriste parcijalni koeficijenti sigurnosti tako su ona znatno veća u odnosu na opterećenja kranske staze prema SRPS-u što uzrokuje veću procentualnu iskorišćenost preseka pri kontroli napona i stabilnosti prema Evrokodu. Provera ugiba je pokazala obrnuto. Uzrok toga je jedinični parcijalni koeficijent za opterećenje pri zadovoljenju graničnog stanja upotrebljivosti.

\section{LITERATURA}

[1] EN 1991-1-1 Dejstva na konstrukcije

[2] EN 1991-1-3 Dejstva na konstrukcije

[3] EN 1991-1-4 Dejstva na konstrukcije

[4] EN 1991-3 Actions on structures

[5] EN 1992-1-1 Proračun betonskih konstrukcija

[6] EN 1993-1-1 Proračun čeličnih konstrukcija

[7] EN 1993-6 Design of steel structures

[9] EN 1998-1 Proračun seizmički otpornih konstrukcija

[10] Granična stanja čelilnih konstrkcija prema Evrokodu, Zlatko Marković

[11] Metalne konstrukcije, Osnove proračuna i konstruisanja, Dr Dragan Buđevac, Mr Zlatko Marković, Mr Dragana Bogavac, Mr Drgoslav Tošić

[12] Metalne konstrukcije u zgradarstvu, Dr Dragan Buđevac

\section{Kratka biografija:}

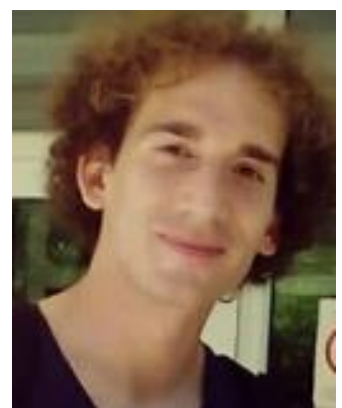

Branko Ilić, rođen je u Valjevu, 1994. godine, oktobra 2017. godine stiče zvanje diplomiranog inženjera građevinarstva. Master rad na Fakultetu tehničkih nauka iz oblasti Građevinarstva, Konstrukcije, odbranio je 2019. godine. 